\title{
Honourable Traditions? Honour Violence, Early Marriage and Sexual Abuse of Teenage Girls in Lebanon, the Occupied Palestinian Territories and Yemen
}

\author{
Pernilla Ouis \\ Faculty of Health and Society, Malmo University, Sweden
}

\begin{abstract}
Girls in the Middle East are often exposed to serious violations of their rights as set out in the UN Convention of the Rights of the Child; these violations are particularly evident in the field of gender-based sexual discrimination and violence. The project described in this article attempts to produce a situation analysis of the exposure to sexual violence of girls aged 12-18 in three countries: Lebanon, The Occupied Palestinian Territories (the OPT) and Yemen. The article focuses on three particular types of gender-based sexual violence against teenage girls, namely honour violence, early marriages, and sexual abuse. The methods applied in the research were Focus Groups Discussions (FGDs) with about 8-12 participants in each FGD. In addition to the FGDs, life stories were also collected. The project emphasised the experiences and opinions of girls regarding the three types of sexual violence listed above. 384 teenagers participated in FGDs to express their views and experiences on sexual violence and more than thirty life stories were collected. The article explores how honour violence, early marriages, and sexual abuse are violations of the CRC and analyses the particular cultural mechanisms that underlie this gender-based sexual violence in the Middle East.
\end{abstract}

\section{Keywords}

gender-based discrimination; sexual abuse; honour-related violence; early marriage; teenage girls; Lebanon; Occupied Palestinian Territories; Yemen

\section{Introduction}

Girls in the Middle East are often exposed to serious violations of their rights as set out in the UN Convention of the Rights of the Child (CRC), particularly in the area of gender-based discrimination and violence. The present project was initiated in 2006 and financed by Save the Children Sweden (SCS) in order to produce a situation analysis of the exposure of girls to sexual violence in three countries: Lebanon, The Occupied Palestinian Territories (the OPT) and Yemen. The research focused on three particular types of gender-based sexual violence against teenage girls in these three countries:

1. Honour violence: In "honour cultures" children are threatened by or exposed to violence in relation to codes of sexual morality and general behaviour. 
In each of the countries of concern here, a number of teenage girls are killed annually. It should be noted that honour violence is not a sexually violent act in itself, but is violence based on the control of the sexuality of women.

2. Early marriage: Marriages involving girls under the age of 18 could be interpreted as cases of sexual violence. This is a serious issue, since such marriages are sanctioned by the legal system in most of the countries in the region. Such marriages are therefore widely accepted in the general culture of the countries studied, and indeed sometimes expected as a matter-of-course. Early marriages are often arranged and may also be forced.

3. Sexual abuse: In addition to honour violence and early marriage, children are also exposed to incest, sexual exploitation and abuse by adults in their closest social environment. In this research project, we have chosen to classify all sexual activities by adults directed towards children as "abuse" and hence as acts of violence. We take the position that children are unable to consent to, or even understand sexual relations with adults. Consensual sex between teenagers is not included in our definition of sexual abuse. Since sexual relationships outside wedlock are associated with strong religious taboos in the Muslim settings we have studied, sexual abuse in these societies is an especially problematic subject for children.

\section{Methodology}

The research was carried out as a co-operation between researchers and local civil institutions that employed a gender and child rights' approach. ${ }^{1}$ I served as the research team leader, travelling to each of the three countries to co-ordinate the research and analyze its results. The following objectives were addressed in each situation analysis:

1. What is the extent of the problem (i.e. the three forms of violence listed above) in each country?

2. How do young teenage girls experience their situation in relation to these forms of sexual violence?

3. What are their opinions regarding the three forms of sexual violence?

4. What are the causes of the problem?

5. What are the measures taken to combat the problem?

1) The three partner organisations were: The Lebanese Council to Resist Violence against Women (Beirut), Women Studies Centre (Jerusalem) and Gender-Development Research and Studies Centre (Sana’a). 
Prior to the primary research, the researchers were requested to carry out a desk review of previous research on gender-based sexual violence in their countries. They were also asked to investigate existing research projects, reports and statistics in each country in order to obtain a substantial background and to be able to draw on already existing research results. Round table discussions with various official representatives as well as NGOs were recommended as a means of complementing the statistics.

For the primary research, Focus Groups Discussions (FGDs) were conducted together with the collection of life stories. A gender perspective is not equal to a female perspective only. To obtain a child perspective on gender issues related to sexual violence, the researchers were encouraged to have a few focus groups discussion with male teenagers as well. These kinds of qualitative methods provided an insider's perspective into the experiences, opinions, and views of the children in the region. The teenagers were selected according to the following defining variables:

- Sex: The research focused on girls. However, it was also recommended to conduct separate FGDs with male teenagers. Male opinions, perspectives and experiences are important since we are dealing with gender-based violence in patriarchal communities.

- Age: Were opinions and experiences among the interviewees dependent on age?

- Marital status: Marriage implies sexual experiences, as well as experiences of early and/or forced marriage.

- Education and employment of parents: Were the problems related to "class" and education?

- Locale: Could trends be identified in accordance with urban, rural or refugee camp settings?

- Religion: The majority of the interviewees were Muslims since the majority of the population in the research settings are Muslims. But it is important to interview minority groups, such as Christians, in order to understand if sexual violence is dependent on religion.

- Tribal affliation: If it were possible, it would be of interest to identify family and "tribal" backgrounds. This variable turned out to be too sensitive for the researchers to identify.

Participants in the FGDs, as well as those who related their life story, introduced themselves in the interview situations in accordance with the defining variables. It should be noted that the participants in FGDs were not selected because they had experienced sexual abuse themselves. Instead, the choice represented the mean of the population of girls in each country. However, the girls chosen to relate their life story also had a personal experience of sexual violence. 384 
teenagers participated in the FGDs, 119 children from Lebanon, 127 from the OPT, and 138 from Yemen. For a qualitative study, a substantial number of adolescents were able to express their opinions on the issue of sexual violence. Part of the results has been published in a report by Ouis \& Myhrman (2007).

\section{Gender-Based Sexual Violence as Violations of the CRC}

We are dealing with the three forms of sexual violence in this study; namely honour violence, early marriage and sexual abuse. These issues are approached from a human rights perspective as articulated in the Convention of the Rights of the Child, adopted by UN General Assembly in 1989. Lebanon and Yemen have signed and ratified this convention, with some minor reservations not directly relevant for our topic. The OPT is not recognized as a state and cannot ratify the convention, but President Arafat endorsed it during his presidency of the Palestinian National Authority and his chairmanship of the PLO. The choice to base our research in the CRC has certain consequences. The first is that the research becomes normative, so that the result can be measured in relation to the CRC. Normative judgements can be expressed when doing so. Secondly, this approach allows for action-oriented research. Its results are somehow aimed at social change. A third consequence of our children's rights approach is that we have chosen partner organisations and researchers with a buman rights agenda.

The first article in the CRC defines children as human beings below the age of eighteen. This is perhaps the most fundamental principle to bear in mind, since we discovered that, within the research setting, teenage girls are viewed as adult women with regard to sexuality. The most obvious case of violations against this article is when children are married and become mothers before they become adults, which is analysed under the heading of "early marriage." Many of the specific problems associated with gender-based sexual violence are linked to the fact that these children are considered to be adults in their societies. The most extreme examples of this problem are the previously mentioned child mothers in addition to the frequent use of child labour. But there is also a problem facing children in honour cultures generally, since they are seen as morally mature and are expected to adhere to the strict moral code of honour operating in society. Consequently, they are not excused because they are children. It has been said that "childhood" is a Western construct. This may be so, but in the CRC the parties have agreed upon this view and on the notion that a childhood associated with special rights is beneficial for the development of the human being.

The second article guarantees the child freedom from discrimination on any grounds, including sex, religion, ethnic or social origin, birth or other status. In this project we have studied a typical form of gender-based discrimination. This is not to say that boys do not suffer from the same kind of problems: boys are also 
subjected to sexual abuse and early marriages and are also oppressed by honour values. However, we believe that girls carry a heavier burden in an honour culture and pay a higher price in early marriages than boys do.

The principal stipulation of the third article reads as follows: "In all actions concerning children ... the best interests of the child shall be a primary consideration." In cases of early marriage we can conclude that it is not in the best interests of the individual child to be disowned of their childhood. Sexual violence and exploitation are cases when children are objectified and their status as human beings have been disregarded. The issue of the responsibilities of safeguarding the interest of the child is further raised in article 5, which stipulates that

States Parties shall respect the responsibilities, rights and duties of parents or, where applicable, the members of the extended family or community as provided for by local custom, legal guardians or other persons legally responsible for the child, to provide, in a manner consistent with the evolving capacities of the child, appropriate direction and guidance in the exercise by the child of the rights recognized in the present Convention.

The parents and other guardians have an important role to play in the protection of children from sexual violence. However, in the Middle East parents in a sense misunderstand their responsibilities as they sometimes force their children into early marriage as a mean of "protecting" them. Furthermore, honour-related violence against girls is nearly always committed by family members. Their role and neglect must be emphasized, which can be seen as a violation of the next article (6) implying the maximum support for the survival and development of children. Honour violence, which sometimes leads to the death of the child, obviously jeopardizes the survival and development of children.

The group of articles from 12 to 14 deal with issues in relation to the child's right to express his or her view, freedom of thought and to have access to information and so on. These articles have been violated in the case of forced marriages and sexual intercourse with children; the voice and opinion of the child has not been heard. However, not all child marriages are by definition forced ones, since it may be easy to convince a child, who is "naive," to marry. Again, the role of parents in such situations, especially given the dependency and trust of the child vis-à-vis the parent, must be stressed. The decision regarding whom and when to marry is fundamental to each individual's life, and should be taken by mature adults free from any kind of pressure, either physical or psychological. Child marriages (i.e. involving persons below the age of 18) violate these rights. In the countries of concern for this study, marriage is allowed below the age of 18 .

It is important to stress the parents' role in reproducing sexual violence against girls in the region. Article 18 in the CRC relates to the role of parents and guardians. The article also indicates the role of governments to assure that parents have the facilities to care for the children. Political instability and economic 
underdevelopment sometimes force parents to marry off their daughters early. It is the responsibility of the governments to provide welfare structures for its citizens, including children.

Article 19 deals with violence, saying that each child has the right to protection from "all forms of physical or mental violence, injury or abuse, maltreatment or exploitation, including sexual abuse, while in the care of parent(s), legal guardian(s) or any other person who has the care of the child." Since commercial sexual abuse is not a major problem in the Middle East, it is important to focus on the role of parents and guardians in cases of domestic gender-based sexual violence. Article 24 is applicable when it comes to honour related violence, which could be seen as a "tradition." Honour violence has been understood by the UN as a harmful traditional practice, but focus has predominantly been on female genital mutilation (Connors, 2005: 29). Article 24 is addressing the right to health, to access to health services and to be protected from traditional practices prejudicial to the health of the child. Hence, children should be protected against harmful traditions and honour related violence and early marriages could definitely be categorized as such traditions with negative consequences for children's health. The medical risks of early pregnancy and childbirth are well documented, but we also want to emphasize the psychological aspects of a "stolen childhood."

Articles 28 and 29 both deal with the right of the child to education on the basis of equal opportunity. In our research project it was discovered that punishment against girls includes house arrest and the denial of education for honour reasons or for refusing to marry spouses selected by the family. Again we find cultural specific traits in gender-based violence violating basic children's rights. Furthermore, an early marriage in practice means a denial of the right to education, unless the state can provide schools for young mothers.

Article 31 deals with something important from the child's perspective, namely the right "to rest and leisure, to engage in play and recreational activities appropriate to the age of the child and to participate freely in cultural life and the arts." Furthermore, States Parties should "respect and promote the right of the child to participate fully in cultural and artistic life and shall encourage the provision of appropriate and equal opportunities for cultural, artistic, recreational and leisure activity." Girls in honour cultures are denied leisure time, or to play with boys, as they are kept inside and are subjected to strong moral rules. Certain types of play are seen as inappropriate even for very young girls. Playing games and bicycling for example are not always accepted for girls in many honour societies because of the fear of "losing virginity" during such activities. ${ }^{2}$ In my previous study in the

2) The issue of the existence of a hymen and the subsequent idea that virginity is a physiological state that can be "lost" is questioned in modern medical research. It has been recognized that no "hymen" exists, but rather a small fold of mucous membrane in the vagina, see Cinthio, 2007. 
Middle East based on interviews with teenage girls, one important opinion expressed in several settings was the girls' wish that it would be accepted in society for them to be friends with boys and to play with them as mates (Ouis, 2005). This could be seen as a wish to be perceived as a child by society and not as a sexual subject. This is a wish that should be encouraged according to the CRC. Furthermore, the girls' right to rest, play and leisure is violated because they have to stay inside the homes to be "good girls." At home, they are often expected to carry out rather heavy domestic work. This connects to the next article (32): "States Parties recognize the right of the child to be protected from economic exploitation and from performing any work that is likely to be hazardous or to interfere with the child's education, or to be harmful to the child's health or physical, mental, spiritual, moral or social development." This article also stipulates that the state must set minimum ages for employment and regulate working conditions. Teenage girls in the Middle East are often required to do unpaid, domestic work. This is child labour, but somehow neglected in the formulation of this article. Domestic work also affects the child's education, health and development negatively and should not be forgotten in this context.

Articles 34-36 deal directly with various forms of sexual abuse of children. Because of the topic of this report, these articles are quoted in full below (note: short version of the CRC):

Article 34: States Parties undertake to protect the child from all forms of sexual exploitation and sexual abuse. For these purposes, States Parties shall in particular take all appropriate national, bilateral and multilateral measures to prevent: (a) The inducement or coercion of a child to engage in any unlawful sexual activity; (b) The exploitative use of children in prostitution or other unlawful sexual practices; (c) The exploitative use of children in pornographic performances and materials.

Article 35: States Parties shall take all appropriate national, bilateral and multilateral measures to prevent the abduction of, the sale of or traffic in children for any purpose or in any form.

Article 36: States Parties shall protect the child against all other forms of exploitation prejudicial to any aspects of the child's welfare.

Children have the right to protection from all forms of sexual exploitation and sexual abuse and no one objects to these articles. However, the sexual abuse of children can be considered "legal" when it is committed within the framework of marriage and thus hidden from public view. We suggest that such marriagesmay they be forced, temporary or so-called "tourist marriages" - are forms of sexual abuse and therefore violations of these articles. We are aware that this suggestion may be seen as controversial since such marriages are legally accepted in Middle Eastern society. In the First World Conference against Commercial Sexual Exploitation in Stockholm 1996, the question was debated whether early and forced marriage is a form of sexual abuse of children. The issue was controversial among the Arab delegates, but Suzanne Mikail from ECPAT (End Child 
Prostitution, Child Pornography and Trafficking of Children for Sexual Purposes) stated that: "If we identify prostitution as an economic transaction with no consent from the child, then the situation could be identical in forced marriages. There is no consent, and it is an economic transaction because the deal is done through the parents" (Hamdan, 2002). Parents are important stakeholders in combating sexual violence, but the legal system is also responsible for the sexual abuse of children, if the marital age is not increased to 18 .

As will be evident in this study, the societies in the Middle East have weak resources for dealing with victims of sexual abuse. In honour cultures, the attribution of blame for sexual assault and rape is on the victim, not the offender. Sometimes imprisonment of the victim is the only protection from violence and killing in the name of honour. Article 37 deals with juvenile justice and could be applicable in the case of imprisoning the victims of sexual abuse. The article stipulates that

[n] o child shall be subjected to torture, cruel treatment or punishment, unlawful arrest or deprivation of liberty. Both capital punishment and life imprisonment without the possibility of release are prohibited for offences committed by persons below 18 years. Any child deprived of liberty shall be separated from adults unless it is considered in the child's best interests not to do so. A child who is detained shall have legal and other assistance as well as contact with the family.

To imprison victims year after year is definitely a violation of these children's rights.

\section{The Honour Ideology}

In order to understand the research results from the three countries, I will explore each form of violence and relate it to the empirical results. ${ }^{3}$ The three forms of violence are interconnected, as will be evident below, but I argue that the basis of the specific structure of gender-based violence has its roots in honour values. Therefore a substantial in-depth theoretical analysis of the notion of honour (sharaf in Arabic) is necessary. I have chosen to label honour values honour ideology, since ideology deals with mental constructions (i.e. values, traditions, ideas) related to power, instead of the often-used term honour culture. It is an ideology oppressing particular groups while giving power to others based on gender and sexuality. Basically, I believe that it is the honour ideology of the culture that needs to be questioned and scrutinized from the perspective of sexual violence against female children. The honour ideology is definitely a fundamental cultural trait determining gender roles in several countries in the Mediterranean region as

3) The results are taken from Ouis \& Myhrman, 2007. 
well as in parts of the Middle East and Asia. The relationship between Islam and honour ideology needs to be clarified from the start: Not all honour cultures are Muslim-honour ideology is found among Christians and Hindus, as well as other religions - and not all Muslim cultures adhere to the honour ideology. However, Islam can serve as a double-edged sword by either encouraging conservative, honour values with reference to Islamic sexual morality, or by combating the honour tradition by reference to it being un-Islamic, and not prescribed in the holy texts.

So, what is honour? It can be defined in several ways. The anthropologist Julian Pitt-Rivers defines honour as the value of a person in his/her own and others eyes; it is a person's evaluation of the value of him/herself in a social context. Honour, can be said to be a person's demand and right to pride and respect (Pitt-Rivers, 1965: 21). Honour is a state that can be lost and this state implies shame, and honour is often associated with men and shame with women. It has been suggested that honour in kinship societies are reflections of the ability of a person to live up to the cultural constructed standards of "masculinity" and "femininity" (Sirman, 2004: 44). In the Middle East, these gender roles imply that men are powerful and dominant, sexually active, providers while women are seen as submissive and weak, sexually passive and working in the domestic sphere. Women have primarily a reproductive role, and men are obliged to guard and control their sexuality. Those who transgress the honour norms are punished with violence. We have defined this violence as "sexual" since its basis lies in sexual norms and behaviour. However, honour violence it is not a sexual act in itself in the way that early marriages and sexual abuse are.

We can discern a distinct honour ideology in all three countries in our study, judging from both the primary and secondary sources. Based on the children's answers and definitions of honour, we can conclude that honour is related to the control of girls' morality and the repression of any act that can be interpreted as an interest in the opposite sex. In all these countries, the girls expressed the view that they are under tremendous pressure not to get a bad reputation and bring shame upon their families. The acts that can do so are various. In Yemen, wearing a decorated, Islamic dress (i.e. covering the head and the whole body) or laughing in the street is sufficient to get a bad reputation as being a loose girl. The children reveal rather shocking stories of how girls are being punished in the name of honour. Furthermore, the studies show that honour ideology reduces a girl's entire characteristics and personhood to the matter of how well she can keep her honour and control her sexuality. This can be exemplified with the following quotation from the Yemenite study: ${ }^{4}$

4) Quote from chapter 4 "Development Struggles versus Poverty and Traditions: Sexual Violence against Female Teenagers in Yemen" by Ishraq Ahmed El-Eryani et al., (Ouis \& Myhrman, 2007), page 117 . 
The issue of women's honour is in the domain of culture, religion and law in Arab and Islamic communities, which fosters the culture of violence and subjugation against women. Women's existence is diminished to being a sexual symbol, which signifies family or tribal honour because the concept of honour in this society has become considered as being similar to common property, which is under guardianship of brother, father, husband, brother-in-law, or other male relatives. This reality indicates that a woman is confined to her body, which is restricted to its sexual dimension; therefore the common concept of honour focuses on this sexual idea at the expense of other dimensions of women's entity and existence. Some of the laws, customs, and traditions that are more powerful, although unwritten laws, back up this idea: the ownership of a woman, where only her body matters.

Honour ideology is a tribal, pre-modern phenomenon. Honour is important for the welfare system in traditional kinship societies, particularly if the welfare state is weak and not fully developed. Honour has functionalistic, economic and materialistic aspects such as maintaining the wealth or land within the tribe or wider family. Women have the right of inheritance and their own money, and the wider family does not want to lose this wealth to another family/tribe through marriage outside their own group. A functional understanding of cultural norms could "explain" that the identity of the group and the maintenance of their wealth are upheld by endogamy, that is marriage within the limited group. In kinship societies, sexuality is connected to relations between communities and power struggles over land, pasture and labour power. It implies that marriage is only acceptable within the group and often consanguinity is practised. ${ }^{5}$ It is understandable that the honour ideology of underdeveloped societies such as Yemen is stronger than in the more developed settings of our study. But political instability such as in the OPT also reinforces traditional structures such as honour and early marriages. The decline and weakening of the honour ideology is definitely interconnected to modernization and economic development, while its maintenance is understood as related to poverty and weak economic development. Nevertheless, the function of the honour ideology can and should be questioned.

Honour can also be viewed as symbolic or social capital, important when economic capital is lacking. Social capital is defined as the advantage created by a person's location in a structure of relationships and implies status and connections in social networks. Social capital is articulated in the notion of repute within the honour ideology: having the repute of being honourable is an important social capital. Hence rumours are important in upholding these structures of power. The French sociologist Bourdieu (2001) refers to honour as a symbolic capital, and this capital provides the social capital essential in kinship societies. Sometimes the reputation of the female (i.e. the social or symbolic capital) is

5) In Progress of Arab Women 2004, it is argued that this practice is promoted by the ideology of patriarchy: "There are many cultural and economic factors that make consanguineous marriages preferable to other unions. Women may feel safer and more secure if they are marrying a relative, property is consolidated, and costs may be saved" (p. 148). 
more valuable and important to the family than the life of the girl herself, such as in the life story of Sanar from the OPT. ${ }^{6}$ Upon finding her 10-year old daughter sexually abused and killed, her mother says: "If her destiny is to die so shall God's will be. But all I pray for is that her chastity is not touched." She stops and then adds: "Thank God. The doctor who examined the corpse when we found her said her hymen was intact and untouched." The reputation of the girl was still an important form of social capital for the family even after her death. However, social capital can be defined by other symbolic assets as well. For instance, education can be seen as a social capital that can replace honour. In the Lebanese study it is concluded that the higher the educational level, the lower the support for honour ideology.

In the course of modernization, the honour ideology is being challenged and questioned. Individualism is a part of modernity, collectivism of kinship societies. This process of transition to individualism is often reflected in the common conflict between individual and collective concerns and interests in terms of marriage. The individuality of the girl is sacrificed for the sake of the honour of the extended family. The Lebanese study reveals this stance in relation to when and whom a girl should marry: ${ }^{7}$

She will feel, more than the man, the impact of breaking up with family traditions, since this breaking up indicates an ambition to achieve a personal value which contradicts family traditions that toil to own the individual and confiscate their freedom, namely girls. A girl continues to represent the honour and dignity of the man, her discipline remains his charge, be it a father, a brother, or later, a husband. Her behaviour can jeopardize the honour of the entire family.

A "shameful" woman that has lost her honour by supposedly promiscuous behaviour, or more often, a reputation of some kind of unacceptable action, must be punished in order to regain the respect and honour of her relatives. Honourrelated violence, and in its most extreme form, honour killings, can be viewed as sanctions against unauthorized love. The honour can be saved if the "crime" is hidden from the public eye, but once it has been discovered, the honour has to be restored either by violence, killings, social exclusion, or by house arrest of the female. Paradoxically, an increased number of honour crimes can indicate modernization and individualism, since it can be argued that the traditional system is responding to an increasing number of women transgressing the traditional borders of honour. Few cases of honour crimes can, on the other hand, imply that socialisation into the honour ideology is successful and few individuals are

6) Chapter 3 "Political Instability and Nation-Building: Sexual Violence against Female Teenagers in the Occupied Palestinian Territories" by Ayesha Al-Rifai (Ouis \& Myhrman, 2007: 102-103).

7) Chapter 2 "Modernization in a Multi-Religious Society: Sexual Violence against Female Teenagers in Lebanon" by Rafif Rida Sidawi, (Ouis \& Myhrman, 2007), p. 30. 
breaking with traditional norms. Therefore the number of honour killings is difficult to interpret without a historical record. In this context it can be noted that Lebanon has had about the same rate of honour killing (approximately 12 per year) since 1958, according to the Lebanese desk review of this project.

In reality, sexual activities are seldom involved when sanctions in the name of honour are imposed. It is the collective will (be it the family, clan or tribe) that grants permissions relating to marriage. In the case of teenage girls, it is seldom a question of sexual relations or even of love or of choosing a partner. Instead, it is often merely a case of girls being seen together with boys or behaving inappropriately. In a report on honour-killed women in Jordan, Amnesty International in Sweden (2005) suggests that $90-95 \%$ of the victims are reportedly "virgins." And the victims are very young. The same report suggests that $70 \%$ of the victims are between 15 and 27 years old.

Many felt that the reputation of the girl was worth everything, even at the expense of her well-being or life. Girls expressed feelings of control and restriction. However, many girls also articulated satisfaction with the honour ideology. They had often internalised the view that women are to blame if they are sexually harassed, noting that they probably encouraged the men, or simply that they were in the wrong place without a male relative to guard them. In the MENA (Middle East and North Africa) region, which includes the three countries of our study, the female victim's honour is saved if the rapist marries her. Such an "offer" gives the offender a penalty reduction or sometimes no penalty at all (Ouis, 2005: 43; Wikan, 2003: 58). It is not surprising that the girls agree with the ideology that has disciplined them all their lives. In Yemen, many girls expressed satisfaction with the honour culture and agreed with the idea that honour is restored if the rapist marries the girl.

However, in Lebanon we found more girls questioning the honour ideology. To be able to reflect on and question the honour ideology is a sign of change. The Lebanese part of our research gives substantial insights into the internalisation of honour values. We argue that the more the honour ideology is internalized, the higher the ratio of submission to status quo. However, dissatisfaction with it does not necessarily mean that there is a struggle against it. $58 \%$ of the girls and $24 \%$ of the boys in the FGDs in Lebanon stated they were dissatisfied with the honour culture. $83 \%$ of the male sample rejected honour violence, which is a remarkably high number. In contrast to this results, the consent with honour ideology was high in Yemen and the OPT, as well as in poorer areas of Lebanon. Here, the adolescents answered questions on how they would like to combat honour violence in such ways that it became evident that they had internalised the view that victims are to be blamed. These answers, particularly from Yemen, reveal that children think and act within the framework of honour ideology. They could for instance say that a girl is sexually harassed and exposed to sexual violence if "she allows" it herself. Despite the fact that they had "reservations against killings," as 
stated in the report from Yemen, the children promoted harsh punishment for the girls and very few showed an understanding attitude. The bottom line was that it was the girl that had erred and consequently had to be corrected.

Honour crimes differ from so-called crimes of passion committed out of jealousy in several ways. However, the legal system in the studied countries is lenient since honour crimes are often judged as passion crimes. Often the sentences are only a few months of imprisonment. It has been debated if honour violence is similar to "regular" patriarchal violence committed by men against women; whether the same mechanisms are expressed in different cultural setting. We oppose this view. It should be stressed that violence in the name of jealousy and male dominance is committed by single individuals. The crime is condemned by society. In the case of honour crimes, however, a whole group of relatives are possible offenders. The crimes are always planned and they have an audience that is symbolically "applauding" the act since the honour has been restored (Kurkiala, 2005: 177-186). Moreover, men and women can be both victims and violators in an honour culture, although the most common pattern is a male offender and a female victim. Hence we have kept the label of honour violence as "gender-based violence." The more common forms of domestic violence occur in the region in addition to honour violence.

Based on evidence in the present study, we can draw the conclusion that tribalism still plays an important role in the Middle East. A trend that is identified in Lebanon is that honour murderers nowadays belong to the victim's nuclear family. This could indicate that relatives and the extended tribe are less influential on family affairs; honour cases are "solved" without the interference of more remote relatives. In Yemen, we note that all honour violence takes place in private settings, without becoming public affairs. In the other countries, the publicity of the honour crimes mark that honour has been restored. This, however, does not mean that honour violence is non-existent in Yemen. Rather, the stigmatisation of shame in Yemen is so traumatic for the entire family that all cases must be hidden from the public eye. For this reason, we argue that the importance of honour as a social capital is much higher in tribal Yemen than in the other two countries. On the other hand, the practice of secrecy could be positive if the family shows a sympathetic and forgiving attitude towards the intended victim.

To our knowledge, there is no study or research that fully has investigated how much violence, or threats of violence, these girls are exposed to. The number of honour killings vary but Amnesty International suggest that 5000 femicides are committed in the name of honour annually in the world. The research of secondary sources in this project indicates the following numbers: Lebanon had 36 cases of honour killings between 1995 and 1998, the OPT had 27 femicides in the year 2005 according to official police records (but 29 according to a women's organisation) and about 400 women in Yemen between 1996 and 1998 are reported to have been the victims of honour killings (here the secrecy surrounding honour 
killings adds further to the problematic of counting victims). It should be pointed out that these figures are highly contested and may well hide the factual cases of honour killings, since honour crimes often are reported as cases of missing persons, accidents or even suicides. Our research in the OPT reveals that the methods for honour killings in the West Bank during 2005-6 included knife attacks, strangulation, being pushed from heights, beatings with a metal bar, being shot in the head, and several cases of poisoning (Al-Rifai, 2007: 74-75). Attempted honour killings are never reported. In Jordan, Amnesty International (2005) suggested that the actual number of honour killings is four times higher than the official numbers. To a certain extent, suicides are related to the issue of honour, since girls may be in such a critical situation that they choose to take their own life. This happens, for instance, when they become pregnant or are forced into a marriage against their will.

Honour killings are the most extreme cases of honour violence, but only the tip of an iceberg of every-day violence against girls in the name of honour. And still, violence in itself constitutes only a fraction of all the outcomes of honour ideology. Most victims are victims only to the extent that they have become socialised to conform to the honour ideology through threats of violence and murder. They have internalised the honour ideology, as discussed above. In many cases, the girls that have participated in the present study agree with the honour ideology and do not critically reflect upon it. In Yemen, it was noted that the children suggested rather strong punishments as ways of combating honour violence. In a way, our definition of honour violence was not clear to them, as they believed that strong sanctions and violence would make girls abstain from going against the honour ideology. Hence, they never saw the honour ideology as something incorrect, that it is the creator of inhuman rules for children to follow. Honour values were accepted as a matter of fact. They sometimes believed that Islamic laws, government punishments, or home detention were better forms of punishment. But in our opinion, the problem is the honour ideology itself, not teenage girls behaving like children. The ability to reflect upon values and a subsequent raising of awareness can be trained with value clarification exercises. Save the Children, Sweden has developed the so-called Ellen methodology for teenage girls, which is a method we are suggesting for empowerment also in this region. ${ }^{8}$

8) In the introduction to Ellen it is said that: "Girls often find themselves the victims of doubly unjust power structures_-children are subordinate to adults, women are subordinate to men. There is therefore a real need among teenage girls for an opportunity to talk about important issues, strengthen their self-esteem and become more aware of their rights. The Ellen project provides girls with access to young adults who have time to listen to them and take what they say seriously, which is something that a lot of young people today do not have." The official translation (2005) of Ellen Handbook by Anna Lundgren and Marie Svensson, Save the Children Sweden, 2002. 
We believe this is a way to help girls not to blame themselves for being children, but to be able critically to evaluate certain norms and rules of behaviour in society.

Education and the rural-urban dichotomy were the only defining variables which indicated distinct differences in how the interviewees understood honour ideology. We can discern a small gender difference in the opinions on honour. As stated above, boys in Lebanon were more satisfied with the honour values than girls. In this more modernised country, $92 \%$ of the girls identified honour with general human morals and only $8 \%$ of the sample linked it to sexual behaviour. However, most answers in both the OPT and Yemen associated a girl's honour to her sexual behaviour and ways of dressing and so on. In Yemen, it was noticed that honour for men was to abide by the religious rules, not to drink, smoke and flirt, to take care of family and to be generally responsible. Honour for boys could be interpreted as being connected to good behaviour in general and not just the sexual morality that relates to girls. The protection of a girl by a male relative is so important in Yemen that she can be accused of losing her honour if no man lives in her house (male parents and guardians may have emigrated or died). Another important gender difference in relation to honour was discerned in OPT. In the FGDs male adolescents stated that since sexual violence against boys is not related to honour and the loss of "virginity," boys are more vulnerable and exposed to sexual abuse and rape than girls. In Lebanon $77 \%$ of the boys were satisfied with the honour ideology, while $23 \%$ considered it both good and bad. The problematic issue with a concept such as "honour" is that it has both positive and negative implications. To be responsible and respected in society is good, but to be violent is bad according to all human rights standards. The Lebanese partner organisation in this project has suggested that the word "honour" could be exchanged for the concept of "dignity" defined as being non-violent and not related to the control of female sexuality. Such alternatives could preserve good things in honour culture while renewing it. It is a common misconception that cultures are static; they are always undergoing change albeit slowly.

Women and teenagers being threatened by honour related violence, have difficulties in finding shelter and legal protection. One way of "solving" the situation has been to imprison women in order to protect them from their families. Women voluntarily accept being jailed for the sake of their own protection. They can be detained in prison for years, and in this situation they are declared "not of age" or incapacitated and can only be released by a male relative. Such male relatives must assure not to hurt or kill the woman, but reality has proven this promise to be of no value. Many women released by their male relatives are killed shortly afterwards. Therefore, many women prefer to stay in prison year after year. Unfortunately, the situation studies in the three countries were not able to provide exact data of this specific situation. 


\section{Early Marriage}

Under the definition of violence in CEDAW (United Nations Convention on the Elimination of All Forms of Discrimination against Women) and CRC, early marriage is considered a form of violence against women and children. Article 16.1 of CEDAW establishes equally for men and women in terms of: "(a) The same right to enter into marriage; (b) The same right freely to choose a spouse and to enter into marriage only with their free and full consent." Furthermore, article 16.2 states that " $\mathrm{t}]$ he betrothal and the marriage of a child shall have no legal effect, and all necessary action, including legislation, shall be taken to specify a minimum age for marriage." General Recommendation No. 24 focuses on the elimination of discriminatory practices related to marriage and to the health of women. Child marriages are categorically viewed as illegal and discriminatory. Governments are required to enact and enforce effectively laws that prohibit marriage of girls. CEDAW and CRC, can function as a valuable instrument for action to bring about transformation and change.

In Islam and according to traditional norms, girls and boys may be married as soon as they reach puberty. Girls are legally allowed to marry below the age of 18 in all the countries of this study. In neighbouring Jordan a recent change in the law put the marital age at 18 for both genders. In the region, women are expected to marry in order to secure their future, since it is the most reliable economic security for women. In most Arab cultures, a woman gains her value by producing many children, and hence a young wife is preferred for this task. In addition to this, poor families may choose to marry off their daughters early in order to get one less mouth to feed and to get their hands on the bride-price. ${ }^{9}$

Early marriage often means early motherhood in addition to a lost childhood. In the report Children having Children: State of the World's Mothers 2004 (Save the Children US, 2004) the following facts are set out: One of ten childbirths in the world is by a mother who is a child herself. Teenage mothers are twice as likely to die from causes associated with pregnancy and childbirth than older mothers. Maternity mortality is five times higher for mothers aged 10 to 14 than for mothers in the age span 20 to 24. In what they label "Early Motherhood Risk Ranking," Yemen is ranked 20. African countries commonly have the highest ranking, but also Afghanistan (ranked 5), Bangladesh (13) and Nepal (17) can be noted as high early motherhood risk countries (SCS 2004). In the Mothers' Index Risk of 119 countries - a list in which a high number is good, Sweden was number one, Lebanon was ranked no 58 and Yemen no 112, while Palestine was not included in the ranking. In the overall Women's Index Rank of 126 countries, Yemen was ranked only 123 and Lebanon no 72 and Sweden was again number one.

9) The bride-price in Islamic societies is often referred to as "dowry" but this is not the correct term. Money and gifts are given to the bride and her family (hence the term "bride-price"), whereas a "dowry" are gods and possessions the girls bring into the marriages and homes. 
Our research reveals that early marriage affects a small percentages of Lebanese teenage girls up to more than $50 \%$ of the girls below the age of 18 in both the OPT and Yemen. This number could be interpreted to mean that early marriage is in decline in modernizing Lebanon, while the political situation of living under occupation has halted such a development in the OPT (Johnson 2006). In Yemen, it is not only the case that a high percentage of girls marry below the age of 18; they also marry at a much lower age compared to the other countries. Marriage involving girls aged 12-14 is common in Yemen and this can be interpreted as a sign of tribalism, weak economic development, and the absence of welfare structures. The children in Yemen stated that early marriage happens for social and economic reasons. The social ones often have to do with taking care of in-laws and carrying out domestic work.

Teenage girls may be forced into marriage at an early age. The term "forced marriage" implies that at least one of the parties has not given his or her consent to the union. In Ouis' study (2005), the notion of forced marriage involving children is problematised. Many young teenage girls "accepted" marriage, since they perhaps were bored in school and had naïve romantic dreams about marriage. The older the girls are, the more difficult it is to "force" them into marriage. It is also difficult to define what a marriage by "force" is, since more subtle means can be used (such as psychological pressure relating to feelings of guilt and love towards the parents). It is "easier" to marry off younger children than when they have matured and grown older.

According to Progress of Arab Women 2004, a report by UNIFEM, women in the region are delaying marriage on average by three to seven years compared to figures in the 1960s (UNIFEM 2004: 145). Furthermore, while marriage used to be almost universal in all Arab countries, we see an increasing number of women who stay unmarried. In Jordan, Kuwait, Morocco, Syria, Qatar and Libya $10 \%$ of the women in the age group 30-34 are unmarried. Being unmarried is a social stigma, and the fear of never getting married may contribute to early marriages. In the situation analysis of this project, we could see that the fear of spinsterhood was a cause for early marriage. The girls interviewed in Ouis' previous study often stated that they wanted to marry after they finished their university studies and had matured and attained some life experience (Ouis, 2005: 66). The ideal was to marry at the age of 25 . However, many girls also expressed that a woman older than 25 had difficulties to find a marriage partner as she would be considered too old. In this study, the Yemenite women are considered "too old for marriage" already at the age of 20 , which is a much lower age compared to the other two countries of concern here. Furthermore, sometimes a university degree or too high an education are obstacles for finding a partner, because educated women are sometimes perceived as strong-headed and problematic. Again, a young, immature girl is preferred.

The wider cultural, political and economic contexts of the region are of importance for analysing early marriages. In a regional workshop organised by SCS and 
the Arab Resource Collective (ARC) in 2001, early marriages were analysed. The report from the workshop pointed out that one significant cause for the continuation of the practice of early marriages is the weak "culture of rights" and "right-based legislation" and their relative ineffectiveness compared to "inherited traditions" (ARC and SCS 2001: 6). This is crucial, and could be related to the issue of honour violence. In cases when the state and its legislation are weak, traditions and tribal norms are more important for the survival and well-being of the individual. The workshop also identified economic pressure, political instability and the attempt to find a better future as causes for early marriages. In the Occupied Palestinian Territories, the marital age is going down for women at the same time as the drop out rate from higher education due to the occupation is going up. Marriage with a local man seems to be a safer option for the future than delaying marriage for studies (Ouis, 2005: 68). In this harsh economic environment, it ought to be of importance for a young woman to have an education or professional skills in case of divorce or the death of her husband. A young, uneducated and untrained wife is in an extremely vulnerable position. World Report on Violence and Health by WHO (2002) states that intimate partner violence against women is likely to be higher the younger the age of the woman.

In the present project we tested the hypothesis that early marriage is a form of sexual violence. This suggestion was discussed in the FGDs in all three countries and was often met with scepticism. Some held the view that this was not the case if the girl had given her consent or if the husband was a teenager too (i.e. it is only sexual violence if the husband is an adult man). In Lebanon, for instance, $76 \%$ of the girls in the FGDs did not consider early marriage to be a case of sexual violence if the girl had given her consent. However, the rest, $24 \%$ of the girls agreed that it was sexual abuse "regardless of circumstances", which could be interpreted as quite many anyway that actually agreed with the statement that it is sexual abuse or even violence regardless of consent. In Yemen, some children even meant that all kinds of sexual acts without the consent of the wife could be labelled as sexual abuse. This is surprising, since it is considered a general "rule" in Islam that wives must be available sexually for their husbands.

Furthermore, the life stories collected in the project give evidence to the hypothesis that early marriage indeed is a form of sexual violence. Below are shocking excerpts of the life stories from Yemen, the country most affected by early marriage and early motherhood. These stories equate early marriage with rape and sexual violence against children. One girl gave the following account:

First, I got married at 11, and second, my maternal uncle married me off. He found the groom through his connections and he was 50 years old. It was a marriage of avarice. My uncle got a bribe of 200,000 rials and my father got 160,000 in money and 300,000 in gold (dowry). Now it is six years since I got married and divorced, and I have a girl from him. I was very young and did not understand life or the meaning of family or how to keep going. My husband was married before me to three women and he has 15 children, and he is well off. 
I entered their family and did not know their life. ... On the day of my marriage I still had not reached puberty and I reached puberty only in his house. He had intercourse with me on the first night, and of course I did not know what a man does to a woman, or how to act, and he penetrated me painfully and my feelings on that night were horrible. I thought he was to kill me and he took me by force. I tried to defend myself that night and I could not and then I fainted and lost consciousness and recovered only in the morning and he left me alone to get rest. And he had intercourse with me on the second and third day and was doing it twothree times a day. It was like being cut and he was insisting on doing it daily and I was begging him and trying to delay it to the last possible moment for him not to get close to me, but he was persistent in what he wanted. Of course, he is a man and he did not marry me for love but wanted me only for his own pleasure and my pain and anguish did not matter to him. For three months after marriage I felt myself butchered and could not tolerate it. I tried to tell him that I am small and cannot but it was beyond my power to protect myself or to persuade him. Everything was, as he wanted, if he was in the mood to have me it was in spite of me, whenever he wanted. I lived with him for two years as if in hell. His other wives were treating me very badly and it was too much and he was going to them and leaving me alone and not talking to me to make my life bearable but then I became content and overcame (kept going). ... I hated him when he came close to me during intercourse. I was not happy or relaxed at all. And he was pleasing himself and thinking only about himself and seeking his own satisfaction (case 3).

We can interpret this case as an act of sexual violence committed against an eleven year old girl by a man in his fifties. From the perspective of the girl, the fact that they were legally married is irrelevant. She was abused and it had consequences for her life. Although not all child marriages are forced marriages, as the next case illustrates, they still affects the parties involved negatively. Early marriage is often a way for girls to escape troubles in the homes of their families, as the next girl tells us:

I am 17 years and I am pregnant now. It is 7 months since I got married. When I got married, my wedding was nice. It was in Jarda'a in Sana'a. Of course, I got married by my consent and I was married for love. He was our neighbour's son and he came to seek my hand and my father did not agree, because there were problems and I insisted and told that I wanted only him. I hated my house because my father had a second wife and was coming and shouting and beating my siblings, and I was the eldest, and I was upset for them. I have 6 siblings, all of them girls. ... It was not a violation, because he made me feel that he cares for me, and when he came to me for the first time, he came with nice words and told me not to be scared and was talking normally to me, and I got uneasy only when I felt blood. I was crying violently and telling him 'enough' but he did not stop and told that some pain is not important because we need to show them the cloth (to prove my innocence) in the morning. When he told me like this, I started to cry more and then we finished, and he was talking to me and made me chew qat. He was talking to me and I was crying, and he was joking and I continued crying and I was shy to talk to him. Every time when I was looking at him, I was afraid that he would say that he would do with me as the first time and also I was afraid that he wanted me to talk to him and I was too embarrassed, and stayed embarrassed for one week. He was telling me to talk to him 'even for money' and I was afraid. ... I did not know what would happen. Of course, I was watching TV but I did not have any experience, and when I was getting married, my grandmother spoke to me and gave me a white cloth and taught me what to do with it and told me not to get scared when he would come to me. Everything was so strange, and I went to him and I was afraid and my mother was crying. ... Every day I was evading him at his sister's room, and he was calling me, and did not want to go to him, and was telling to him to 
come to sit with us in his sister's room, and I did not dare to go with him because he hurt me on the first day. I felt that something was falling out of me and was afraid and the pain lasted for two days. And even when I let him, when he was coming to me, I was crying until he felt sorry for me and I was tired and he continued not to let me sleep and all the time when I fell asleep he was waking me up. I was afraid and felt at ease only after one month. ... Early marriage is not good. They should leave girls until they understand life and have studied and if they get pregnant, they do not get tired, and leave boys until they are grown up and working. My husband is 21 years old, but he is like a child in my view, and he is still playing footfall in the street with children, which is normal for him and he is very immature, though he is already 21 ... I did not get anything from early marriage. I was running away from problems and got into a bigger and worse problem. My mother-in-law suffers from diabetes and high blood pressure and she always makes problems for me and shouts. Sometimes my husband brings biscuits for me only, and she yells why he brings only for me and not for the whole house, and my husband does not have money and for some time he is not working (case 6).

\section{Another Yemenite girl aged 15 witnesses how the first night of intercourse made her hate her husband:}

I do not remember the first word he said to me and I did not want to talk to him because I was embarrassed, but he is a man and men do not feel shy. Only women feel shy. I did not feel love or desire for my husband. ... I did not want him at all, but I wanted to get decorated and cook and go out with women, and I did not want to stay with him at all. Yes, he is my legitimate husband, but by God's grace, I did not want him from the first night. Even his smell, I could not stand it. We did not live together at all, though I got pregnant from him twice, but I did not want him or love him. When he came to me on the first night, I was afraid and did not allow him to touch me, and he was violent and wanted me by force, and every time he was approaching me, I was closing my eyes and nose. I was serving him and the whole house. Everything was fine, except sleeping with him, which I could not stand and did not want. He was taking me by force when he wanted me and I was crying sometimes and sometimes he was expelling me to my parents (case 8).

The situation analysis in the three countries provided several examples of the experiences of early marriage among teenage girls. In general, they are against it, although they do understand the point of view of the girls involved and their families. The voices of the girls are important for future work against early marriage in the region. A first step is to work for the marital age to be set at 18 in the region. However, the work to change customs and traditional attitudes towards early marriage is a hard battle.

\section{Sexual Abuse}

We take the standpoint that all forms of sexual abuse of children by adults are classified as violence. We argue that children should be protected from all forms of sexual intercourse with adults, and that such acts are violent and against the best interest of the child. Sexual abuse of children exists in all societies, but the recognition of and attention to this particular form of violence against children 
varies from society to society. Unfortunately, the countries of concern in this study have not openly admitted having this problem. The taboo on sexual abuse of children in the region can be attributed to the great shame associated to sexual relations outside marriage and the honour ideology previously discussed. Furthermore, it is an issue that most people prefer to keep in the private sphere, and not to debate openly in public, since it damages the self-image to acknowledge that such problems actually exist in their societies. Recently, telephone helplines have been introduced for women and children in Jordan, Yemen and the OPT. In personal contacts with those organising these help-lines it has become apparent that the sexual abuse of children exists in the region to a larger extent than expected. In addition to this, few studies have been undertaken to investigate the extent of sexual abuse of children in the region, so governments and media can continue to be silent about the issue. One of the exceptions is a study from Syria that describes some of the mechanisms in relation to the sexual abuse of children (Moussa, 2005: 22). Although the report does not provide any figures of the scope of the problem, it gives an important cultural background to the problem. In the report, it is argued that "sexual assault" is considered a "social disgrace" and "a scandal" for the child and his or her family. It is noteworthy that shame is associated with the victim, not the offender. By being the victims of sexual abuse, children are exposed to the risk of being killed by the family or forced to marry the rapist in the name of honour. The report suggests that children are afraid of reporting abuse because of the punishment and bad treatment they expect from parents. When cases are made public, the "assaulted child will be put in a reform institute for delinquent juveniles and is not handed over to their parents for fear of harsh parental punishment" (ibid). This shows the extremely difficult and complex situation for children in the region with regard to sexual abuse. The honour ideology not only blames the victims but makes families take action against them.

Our research shows that children indeed have the experience of sexual abuse in all three countries studied here. Children reveal several cases, often within families, and they are well aware of the problem. Their suggestions for how to combat the violence must, however, be contextualized. Some children suggested that the Islamic dress code could be a protection against sexual assault and abuse (a suggestion even supported by Christian groups in the OPT). But the effectiveness of this idea can be questioned through the findings of the reports. In the situation analysis from the OPT, it is pointed out that even girls wearing this clothing are sexually assaulted, and that such a view "gratifies the perpetrator's sexual drive as aroused by a tempting dress or so." The suggestions from the Yemenite children were based on the assumption that by guarding and controlling children better they could be protected from sexual abuse. In a way, they considered children as active participants whenever sexual abuse occurred. It is our standpoint that 
children are innocent victims in such cases. It is the adults that are responsible and to blame whenever sexual abuse of children has taken place and therefore the focus in actions to combat the problem should be directed towards adults.

A topic of debate in the FGDs was whether extra-marital consensual sex is sexual abuse since it is "illegal" according to Islamic law and customs. In the OPT, rural girls from Hebron defined sexual violence as "illegal sexual relations," while their counterparts in Jenin considered rape and love affairs between teenagers as two different forms of sexual violence. In Yemen, the children differentiated between cases of sexual violence where one party has not given consent to intercourse, and cases of consensual sexual relationships where consent was given. Examples of such relationships were sodomy, adultery and secret marriages, the latter being a particular "problem" often mentioned in Yemen. In the definition we chose, consensual sex between teenagers is not considered a form of sexual violence, but were somehow perceived as such in some FGDs. Thus, the suggestions of the children in Yemen of "marrying the sinners" do not apply according to our definition, since that would be to suggest that the rapist should marry the victim, a view we strongly object to. However, we do not moralise over consensual sex in this study, and hence "secret marriages" is not sexual abuse in our definition.

During the first World Conference against Commercial Sexual Exploitation (held in Stockholm in 1996), a universal declaration vowing to draft national plans of action against sexual exploitation of children was drafted. Some Arab countries signed the declaration. Unfortunately, very little of this pledge has been put into practice. The second conference of this kind was held in 2002, and sexual abuse got some attention in Arab media after that. It was recognised that the worst forms of organised sexual exploitation of children (prostitution, pornography and trafficking) are not so severe in the region, while it may happen to individual children. It was also said during this conference that men from rich Arab countries (such as Saudi Arabia and the Gulf states) may visit poorer countries in the region and "marry" a deprived girl and then dump her after having sex, leaving no legal documents of their marriage. This so-called "tourist marriage" is nothing but sexual abuse of children, and is becoming a large problem in Yemen and an emerging one in Lebanon. Girls who have married a tourist may be forced into prostitution afterwards. During the conference it was said that most prostitutes had a history of sexual abuse by members in their own families. Victims of sexual abuse are often forced into prostitution when abandoned by their families in the name of honour. In Lebanon, it was discovered that prostitution takes place within wedlock; men marry women legally, but force them into prostitution afterwards (Hamdan, 2002).

The tourist marriages are briefly discussed in the project in the section about Yemen, but more research is needed to evaluate its extent and consequences. "Secret marriages" in urban Yemen or "Islamic marriages" (accepted according to 
Islam, but not legally binding) in the OPT were briefly discussed in the study. The problem for future work is to distinguish if such marriages are based on consensus between two parties or if they are covers for prostitution and sexual abuse. It should also be stressed that many immigrant women working as housemaids, nannies and within other service jobs often are sexually abused in their work places or forced into prostitution. This problem is on the rise in Lebanon where foreign maids for domestic work are more and more common.

A particular form of sexual abuse applies to Palestinian women living under Israeli occupation. It has been reported that Palestinian women are routinely harassed, intimidated and sexually abused by Israeli soldiers and border police. The threats of being subjected to sexual violence and humiliation in public space have been part of strategies of domination by Israel (Song, 2005: 6). Furthermore, the occupation and curfews cause domestic frustrations that can develop into sexual abuse of children. The situation further encourages the practice of early marriages as a security measure, as pointed out in the section from the OPT.

Sexual abuse is a form of gender-based sexual violence that is related to the other forms of sexual violence discussed, i.e. early marriage and honour violence. If a girl becomes a victim of sexual abuse and perhaps gets pregnant, she can be forced into a marriage to cover up for the crime by marrying the rapist or worse, be killed in the name of honour. There are many testimonies from the region about this practice. The anthropologist James Emery reports some shocking cases of incest in the OPT leading to the killing of the victims instead of the offenders. A four-year old Palestinian girl, raped by a man in his mid-twenties, was left by her family to bleed to death rather than "sully their honour" (Emery, 2003). The legal system is problematic in the region, because if a girl has been subjected to sexual abuse, the complaint to the court must be done through a male relative, who possibly even could be the offender. Again, institutionalised patriarchy makes it difficult for girls to raise their voice when injustices have been committed against them.

The Lebanese study produced interesting results on how adolescents view sexual abuse. In the FGDs the hypothetical question was asked whether or not you would report being raped. $56 \%$ of the girls said they would report it, while $17 \%$ said that they would not and $27 \%$ did not answer this sensitive question. The Lebanese researcher provided the following analysis of this result:

Though these percentages show a positive trend within the girls who believe that denouncing a rape would stop the rapist, the percentage of those who would not denounce it, and those who were embarrassed to answer, testify once more to the internalization of social concepts within girls, rendering them the exclusive preservers of honour. These beliefs generate fear, mainly from parents. The latter was expressed in the group of the North, predominantly Muslim, who unanimously announced that they would keep it from their parents, or suffer beating, or even cope with their parents' belief that it was consensual. Other girls in other groups justified their cover up of a rape by fear of their parents or fear for their reputation. 
This shows the extremely difficult position children face in the region in revealing sexual abuse. But it also points towards the interconnections between various forms of sexual abuse. In this case, sexual abuse can lead to honour violence. Even the boys in the Lebanese study felt that they had to keep rape a secret. Up to $50 \%$ gave this answer, showing that sexual abuse is a disgrace to the victim, irrespective of gender. In the male group, they were asked a hypothetical question concerning their reactions if their sisters were raped. More than $50 \%$ showed an empathic, understanding attitude rather than taking a traditional stance and try to marry her off with the rapist or even worse, arguing for violence in the name of honour. However, this sympathetic attitude was markedly decreasing to about only $10 \%$ if the issue was that their sister had had consensual sex.

Thus, there are reinforcing interconnections between the three forms of sexual violence. Sexual abuse can lead to honour violence and early marriage as discussed above. In the situation analysis from the OPT an example of this is given with the case of two sisters aged 18 and 28, who were poisoned to death in the name of honour after it had been discovered that they had been sexually abused by their uncle. Moreover, refusing an early marriage can be punishable by violence in the name of honour. Having said that we must also say that early marriage is an expression of honour violence and sexual abuse in itself. A refusal of early marriage can lead into prostitution. False accusations can force a girl into early marriage or into prostitution and sexual abuse. Hence, all three forms of sexual violence are interconnected and mutually reinforcing each other. The life stories confirm this finding. A summary of the collection of eleven cases in Yemen shows that in each case, the girls have often been subjected to more than one form of sexual violence, such as early marriage and sexual abuse, early marriage and escape leading to prostitution, and accusations of lost honour leading to more sexual violence.

It can be concluded that the honour ideology and the religious and moral rulings do not protect teenage girls from sexual violence and abuse in the region, but rather the opposite. This conclusion was confirmed in the Lebanese study in which $66 \%$ of the male teenagers and $80 \%$ of the girls "concurred that the culture of honour begets sexual harassment and violence against girls." In Yemen, some children stated that the honour ideology and gender segregation makes girls easy prey for male romantic approaches and sexual harassment. A habit of mixing and playing with boys could thus empower girls and increase their resistance to sexual abuse.

\section{Islam, Traditions and Legislation: The Context of Human Rights' Conventions}

It is well known that some Arabic and Islamic countries have made reservations to CRC and CEDAW. The three countries in our study have not made any reservations applicable to the articles raised here, but the general objections from 
Arab states is that the articles can only be accepted if they are not against the Islamic Law, sharia. This poses a problem of how to interpret the Islamic Law. Whose interpretation shall we rely on? Traditionally, only men have interpreted sharia. But we are also faced with the differences of the four schools of thought within sunni Islam, in addition to Shia Islam. In practice, however, traditions and customs mean more to people in most Arabic countries than Islam. Yet in relation to laws and conventions, Islam has a higher legitimacy. I therefore suggest the following hierarchy of legitimacy:

\section{Traditions ( urf) \\ 2. Islam (sharia) \\ 3. Laws (qanun) \\ 4. International conventions}

The other researchers in this project confirmed this model. From Yemen it was reported that informants had stated that even if the law stipulated a marital age of 18 , they would lie about the date of the birth of their children in order to marry them off earlier and circumvent such a law. So, although there are clear violations of the CRC, the usefulness of the convention is limited. Today, we see that the application of the law, as well as the law itself, is influenced by religion and customs. This problematic is further explored in the three research reports. However, change can be brought about by addressing the conventions and promoting the legal system to conform to signed treatises. A sign of modernization is that laws become more important than customs and religious laws. Thus, the work towards adherence of the principles of the CRC and towards a change in the legal system is not useless. Furthermore, there is a new discourse emerging connecting Islam to human rights. Thus, Islam, laws and conventions can together be powerful against customs to create a better situation for teenage girls in the Middle East. Therefore, this context needs to be analysed in detail.

Religion is, as mentioned earlier, a double-edged sword in the battle against honour crimes. The Islamic rule of sharia according to sura (chapter) 24 in the Holy Qur'an states that accusations of adultery must be supported by four witnesses of the actual sexual act. This can be applied as an Islamic tool for categorizing honour killings based on reputation as being anti-Islamic and against the religious law. Unfortunately, these kinds of interpretations are seldom applied. Instead, the religious establishment of scholars and politicians, both Muslims and Christian, often choose to support honour crimes in the name of religious sexual morality and because they regulate who is allowed to marry whom and offer prohibitions against premarital sex. As demonstrated in the study from the OPT, Palestinian priests have supported the killing of Christian Palestinian girls having relationships with Muslim boys, saying that this is a message to others to keep away from such relationships. It seems that the honour ideology somehow finds resonance with religious moral laws within all religions, not only Islam. 
It should be stressed that the moral ideals against sex outside wedlock do not have to support honour crimes, but in practice many religious scholars still make this connection. It is fully acceptable and understandable to have a morality saying that sex belongs to marriage, but the problem is which sanctions should be taken against those who are suspected of breaking these moral rules. We are not encouraging promiscuity or loose sexual relations among teenagers, but we stress the right for children to be children and not to be sexualised or married off at an early age. It should be noted that in the West, there is a tradition coming from Protestantism which operates through individualist feelings of guilt and innocence, while in the Middle East, both in Christianity and Islam, the same mechanisms are coloured by the collectivist honour and shame dichotomy. In the West the individual often feels guilty in regard to what is right and wrong, hence disciplining themselves through feelings of bad conscience. In the honour ideology, shameful deeds can be practised if they are hidden from the public eye. This can be interpreted as encouraging hypocrisy, but it is a structure that releases people from feelings of guilt and provides a space of freedom if actions are kept in secret. However, the honour ideology seems to be repressive at large since the victims of sexual assault are accused as well, and hence will have problems reporting their experiences. Furthermore, the families of a sexual abuse victim are also tainted and stigmatised.

In practice, customs still seem to have higher legitimacy than religion, although I believe a shift of positions will come due to Islamization. In our research, informants argued that honour violence was against religion and suggested that it should be combated through religious sanctions. Islam is also referred to as a tool for gender equality, since it moralises against both sexes and ascribes the same sanctions towards them. In tradition, only the female is blamed as demonstrated in the experiences of the girls. Hence, Islam can be a tool in combating honour violence, and has been used for this purpose, for instance, in Jordan. The strict rules concerning the sacredness of privacy and integrity could be applied to condemn the spreading of rumours and gossip in the name of honour. In Islam, it is a sin to spy on others and spread gossip. However, the same principles make it harder for children to speak up against sexual abuse in their homes, since such matters often are referred to as "private" and hence to be solved in the private sphere without interference of the wider society. The abuse can then continue in secret. Furthermore, the religious stress on the "obedience" of children and wives to fathers and husbands, as pointed out in the OPT report, make it problematic to speak up in cases of sexual violence. Another problem related to Islam, discussed in the situation analysis here, is that within sharia "rape within marriage" is an unknown concept since women must be sexually accessible to their husbands. Young wives are hence exposed to repeated sexual abuse in their marriage as the quoted life stories from Yemen above demonstrate. No rule in religion 
encourages early marriages, but none condemns it either, leaving religion open to interpretation regarding marital age. Hence, religion can be used both for and against sexual violence within marriages.

The legislation relating to honour crimes and sexuality is influenced by religion and traditions. Originally, the laws regarding passion crimes have been influenced by the laws of the colonial powers and are not from the sharia as such. Nowadays, however, they are used as an excuse for lenient punishment in the case of honour crimes. ${ }^{10}$ The law stipulates that the extenuating circumstance for the criminal is his loss of sanity in seeing his wife having intercourse with another man. In honour crimes, however, this excuse is hardly ever valid since such crimes seldom feature a woman being surprised in bed with another man. But the notion of the killer's "fit of fury" is used to apologize honour crimes and to reduce sentencing. Moreover, the law against adultery has been abandoned in the West during the course of modernization, but it is still existent in the Middle East. Such changes of law in the Middle East would make sexuality a private concern, and not an issue of either legislation or tribal custom. Consensual sex would not be equated with sexual abuse if such a change were to come about. A way of having "legal" consensual sex is to engage in an Islamic marriage (urfi marriage) as reported from the OPT. Islam can be used to give legitimacy and blessings to consensual sexual intercourse, in cases where laws and families are opposing such unions. However, the same practice can be exploited for sexual abuse and prostitution.

The legislation against sexual abuse and violence against women and children needs to be strengthened in the region. The three situation analyses give examples of laws that discriminate against women and children. Although Lebanon stands out as the most modernized country in our study, it still has a legislation strongly influenced by religion and traditions. Therefore, the Lebanese women's movement's quest for a unified and secular civil law should be taken seriously. In the OPT, the laws are confusing but the same discriminatory traces are apparent in their legal systems. Apart from the recently established laws by the Palestinian Authority, Gaza also follows Egyptian law and the West Bank practices Jordanian legislation in certain matters.

Our suggestion to use the CRC for combating sexual violence against teenage girls must be considered in the light of the above-mentioned realities of customs, religion and legislation. However, the CRC has been successful in the promotion of new legislation against trafficking and child prostitution in the region. Since such laws exist, they also have to be applied and interpreted so that sexual abuse, violence in the name of honour, and early marriage all are treated as forms of

\footnotetext{
10) This law is deduced from the French Penal Code of 1820 into the Ottoman Penal Code from 1958 (Abu-Odeh, 1996: 143-144).
} 
sexual violence. The women's movement in the region is working for legal changes promoting gender equality. This struggle must be supported and CRC can be applied in this work. In the process of development, laws will be more important than religion and customs. We therefore believe that the CRC is the frame of reference that will be used in future work for combating this problem.

\section{A Swedish Perspective on the Project}

It is important to note that the problem teenage girls in the region are experiencing is not limited to their home countries, but are also prevalent when living abroad. An additional aim of this project was to contribute to an understanding of the situation facing teenage girls with immigrant backgrounds. In Sweden, honour violence and forced marriages have been debated in recent years, but few have investigated the origin of these problems. The problems in Sweden are interrelated with the problems in the Middle East. In Lebanon, for instance, each summer sees the opening of a "marriage market" when the Palestinians and Lebanese living abroad come home for their summer vacation. In this time, families seek a young spouse for their son. Often a very young wife is preferred to an educated woman, and she often happily agrees to the proposal. The youth in the Middle East are often fed with dreams of the "good life abroad" and want a "ticket out," Something which applies particularly to Palestinians living in camps in Lebanon. It has been said that Palestinians living in Sweden influence the marital age of girls downwards to the early teens. ${ }^{11}$

For the teenage girls with Middle Eastern background living in Sweden, the situation is problematic in other ways. They have problems to find a marriage partner in their "home country," since they are considered difficult, strong-headed and "Swedish," all of which are negative attributions. Their honour is sometimes tainted without any specific accusation more than a suspected "Swedish lifestyle." The young men in Middle East that accept to marry them often exploit these girls just to get out of the country. It has to be clear that a residence permit in Sweden is a source of income for the extended family. However, some girls do not accept such marriages. They might have boyfriends in Sweden, which bring the honour issues and forced marriages to the fore again. Furthermore, Ellen discussion groups have been initiated in many cities in Sweden with a high attendance from girls with Middle Eastern immigrant backgrounds.

11) This information was given by personal communication with Mrs Olfat Mahmoud, chairwoman of Women's Humanitarian Organization in the camp of Burj el-Barajneh in Lebanon. 


\section{References}

Abu-Odeh, Lama 1996. "Crimes of Honour and the Construction of Gender in Arab Societies." in Mai Yamani (ed.), Feminism and Islam: Legal and Literary Perspectives, Reading: Ithaca Press.

Al-Rifai, Ayesha 2007. "Political Instability and Nation-Building: Sexual Violence against Female Teenagers in the Occupied Palestinian Territories." in Ouis, Pernilla \& Tove Myhrman (eds.), Gender-Based Sexual Violence against Teenage Girls in the Middle East: A Comparative Situation Analysis of Honour Violence, Early Marriages and Sexual Abuse in Lebanon, the Occupied Palestinian Territories and Yemen, Beirut: Save the Children, Sweden, pp. 69-112.

Amnesty International 2005. Document in Swedish on honour crimes by Katarina Bergehed, from Amnesty's homepage, www.amnesty.se

Arab Resource Collective (ARC) and Save the Children Sweden 2001. Adolescents, Early Marriage and the Convention on the Rights of the Child in Arab Societies: English Summary Report of a Regional Workshop, Larnaca 1-4/3 2001.

Bourdieu, Pierre 2001. Male Domination. London: Polity.

Cinthio, Hanna (ed.) 2007. Hedersrelaterat våld och förtryck: Ett kunskapsunderlag för hälso- och sjukvården ("Honour Related Violence and Oppression"). Länsstyrelsen i Skåne Län.

Connors, Jane 2005. "United Nations Approaches to 'Crimes of Honour'." in Lynn Welshman \& Sara Hossain (eds.), "Honour": Crimes, Paradigms, and Violence against Women, London \& New York: Zed Books, pp. 22-41.

El-Eryani, Ishraq Ahmed et al. 2007. "Development Struggles versus Poverty and Traditions: Sexual Violence against Female Teenagers in Yemen." in Ouis, Pernilla \& Tove Myhrman (eds.), GenderBased Sexual Violence against Teenage Girls in the Middle East: A Comparative Situation Analysis of Honour Violence, Early Marriages and Sexual Abuse in Lebanon, the Occupied Palestinian Territories and Yemne, Beirut: Save the Children, Sweden, pp. 114-161.

Emery, James 2003. "Reputation Is Everything: Honor Killings among the Palestinians." www .worldandi.com/newhome/public/2003/may/clpub.asp.

Hamdan, Dima 2002." Conference May Break Taboo on Sexual Abuse in Arab Countries." Aman Daily News, January 2, 2002 (htpp://www.amanjordan.org/english/daily_news/wmview.php? ArtID=10).

Johnson, Penny 2005. "Living Together in a Nation in Fragments", in Lisa Taraki (ed.), Living Palestine: Family Survival, Resistance, and Mobility under Occupation. Syracuse, NY: Syracuse University Press.

Kurkiala, Mikael 2005. I varje trumslag jordens puls: Om vair tids rädsla för skillnader. Stockholm: Ordfront. (Swedish)

Lundgren, Anna \& Marie Svensson 2002. English translation of the Ellen Handbook, Save the Children Sweden.

Moussa, Daad 2005. Report about Sexual Assault and Exploitation of Children in Syria. Save the Children, Sweden.

Ouis, Pernilla 2005. Woman or Child? Voices of Teenage Girls in the Middle East. Save the Children Sweden.

Ouis, Pernilla \& Tove Myhrman (eds.) 2007. Gender-Based Sexual Violence against Teenage Girls in the Middle East: A Comparative Situation Analysis of Honour Violence, Early Marriages and Sexual Abuse in Lebanon, the Occupied Palestinian Territories and Yemen, Beirut: Save the Children, Sweden.

Pitt-Rivers, Julian 1965. "Honour and Social Status" in J.G. Perstiany (ed.), Honour and Shame: The values of Mediterranean Society. London: Weidenfeld and Nicholson.

Rida Sidawi, Rafif 2007. "Modernization in a Multi-Religious Society: Sexual Violence against Female Teenagers in Lebanon" in Ouis, Pernilla \& Tove Myhrman (eds.), Gender-Based Sexual Violence against Teenage Girls in the Middle East: A Comparative Situation Analysis of Honour Violence, Early Marriages and Sexual Abuse in Lebanon, the Occupied Palestinian Territories and Yemen, Beirut: Save the Children, Sweden, pp. 22-66. 
Sirman, Nükhet 2004. "Kinship, Politics and Love: Honour in Post-Colonial Contexts-The Case of Turkey" in Shahrzad Mojab \& Nahla Abdo (eds.), Violence in the Name of Honour: Theoretical and Political Challenges. Istanbul: Istanbul Biligi University Press.

Song, Joyce 2005. NGO Alternative Pre-Sessional Report on Israel's Implementation of the United Nations Convention on the Elimination of All Forms of Discrimination against Women (CEDAW) in the Occupied Territories (OPT). Al-Haq, Palestinian Centre of Human Rights and Women's Centre for Legal Aid and Counselling (WCLAC).

UNIFEM 2004. Progress of Arab Women 2004.

Wikan, Unni 2003. En fråga om heder ("A question of honour"). Stockholm: Ordfront. (Swedish) World Health Organization (WHO) 2002. World Report on Violence and Health. 